\title{
Franquismo, delincuencia y cambio social
}

\author{
ANA FERNÁNDEZ AsPerilla \\ UNED
}

\section{Franco's dictatorship, delinuency and social change}

\begin{abstract}
RESUMEN
A través de una serie de delitos que proliferaron bajo diferentes etapas de la dictadura, se ofrece una imagen de la vida cotidiana y del funcionamiento de la administración del Estado durante el franquismo en algunos aspectos. La descripción de hechos delictivos, extraídos de sentencias judiciales o denunciados por la fiscalía, permiten conocer las transformaciones sociales $y$ sus consecuencias sobre la criminalidad.

Asimismo, el movimiento delictivo hace posible identificar diferentes estadios de desarrollo.

\section{PALABRAS CLAVE:} Franquismo, Sociedad, Delincuencia, Transformaciones Sociales, Historia.

\section{ABSTRACT}

Throughout a series of crimes which proliferated at different stages of the dictatorship, it is possible to observe an image of every day life ant the functioning of state administration in some stages during "Franquismo". The use of criminal facts described in judicial sentences or denounced by public prosecution, allows us to get to know social transformations and its consequences on criminal acts. Finally, the criminal movement makes it possible to identify different stages of development.

\section{KEYWORDS:}

Society, Delinquency, Social

Transformations, History
\end{abstract}

Las fuentes que registran el movimiento de la delincuencia no interesan exclusivamente a los responsables del Ministerio del Interior, a los criminólogos o a los jueces y fiscales, sino que son también útiles para analizar la sociedad y la administración de un periodo histórico determinado. A cada sociedad le corresponde una pauta delictiva, que ofrece datos de interés para los historiadores'. Por eso en

1 Sobre las formas de la delincuencia y la penalidad, así como su relación con los valores imperantes en cada época, véase Trinidad Fernández, P.: La defensa de la sociedad. Cárcel y delincuencia en España (s. XVII-XX), Madrid, Alianza Editorial, 1991. 
este artículo nos aproximaremos a una serie de tipologías delictivas con un propósito múltiple. Por un lado descubriremos cómo las fuentes judiciales facilitan un mejor conocimiento del funcionamiento de la sociedad ${ }^{2}$. En segundo lugar, observaremos como la evolución de la delincuencia es también un indicador de las transformaciones económicas, permitiéndonos descubrir la incidencia de estas transformaciones tanto en la vida social como en las instituciones ${ }^{3}$. Por último, un examen de las pautas de delincuencia durante el franquismo nos conducirá inmediatamente al tratamiento punitivo y al discurso del régimen. En ese sentido podremos conocer mejor la mecánica y la naturaleza misma de la dictadura de Franco. Todo ello, sin considerar la delincuencia política y su tratamiento que merece, claro está, un estudio aparte.

Después de la Guerra Civil, el círculo formado por la recesión, la política económica autárquica y el mercado negro provocaron una estela de miseria y corrupción. Como consecuencia, en las dos primeras décadas del régimen proliferarían comportamientos delictivos que la dictadura reprimió muy duramente en algunos casos y con lenidad en otros. Concretamente nos referiremos a diversas variedades de robos, como los denominados «hurtos famélicos" en el lenguaje judicial, los robos de energía eléctrica o los delitos cometidos por la burocracia estatal.

Los "hurtos famélicos" consistían en la sustracción de pequeñas cantidades de alimentos como bellotas, aceitunas, etc., o de haces de leña, que se utilizaban como combustible en los hogares en un contexto de restricciones energéticas. En puridad, no se trataba de auténtica delincuencia, pues el móvil de sus autores era la satisfacción de las necesidades familiares básicas, en unas circunstancias de pobreza extrema ${ }^{4}$. Como le ocurrió a un hombre sin trabajo ni recursos "para atender a la subsistencia de su esposa y de su única hija enferma", tras haber vendido los escasos enseres que poseía para comprar comida y medicinas, saltó la tapia de un corral y se apoderó de un gallo valorado en 42 pesetas, que comió con su familia ${ }^{5}$. El carácter agrario de la economía española durante los años cuarenta y el subempleo rural masivo de algunas zonas del país, donde los salarios, extremadamente bajos, descendieron incluso en los primeros años de la dictadura y no se recuperaron hasta 1956, explican la proliferación de robos de subsistencia.

2 JUNTA DE COMUNIDADES DE CASTILLA-LA MANCHA: La administración de Justicia en la historia de España: Actas de las III Jornadas de Castilla-La Mancha sobre investigación en archivos, Toledo, 1997.

3 TohariA, J. J.: Cambio social y vida jurídica en España, Madrid, Cuadernos para el Diálogo, 1974.

${ }^{4}$ Por hurto famélico se entiende el realizado «por un indigente para aplacar su hambre o cubrir su desnudez" (cfr. JIMÉnEz dE AsUA: Tratado de Derecho Penal, IV, 1952, pàg. 434, citado en RodRiguez DEVESA, J. M.: "Necesidades de un nuevo planteamiento de la problemática del hurto famélico", Revista de Estudios Penitenciarios, 162, (1963), pàg. 495). El ejemplo típico de esta clase de hurto es el protagonizado en el s. xix por Luisa Ménard, sin otros recursos que dos kilos de pan y dos libras de carne, que le entregaba para la semana la beneficencia en Charly, para ella, su madre y su hijo. Sin trabajo ni dinero y después de 36 horas en las que ni ella ni su madre habian tomado ningún alimento, habiendo dejado al niño unas gotas de leche que había en la casa, sustrajo de casa de un pariente un pan que comieron inmediatamente.

5 Cfr., según sentencia de 7 de febrero de 1958 (Aranzadi, 347). 
Estos delitos contra la propiedad, que solían producirse en el campo, ocuparon muchas páginas de sumarios judiciales en el período de la autarquía. En algunas provincias alcanzaron cifras muy elevadas, superiores a las del resto de delitos del Código Penal y de las Leyes Especiales, según afirmaba el fiscal general del Estado en 1948. Como consecuencia, al margen de los presos políticos, que eran la mayoría de los penados, los reclusos comunes condenados por robo $u$ otros delitos contra la propiedad habían delinquido impulsados por las necesidades provocadas por los desfases socioeconómicos de la posguerra. El noventa por ciento eran delincuentes ocasionales, pues apenas existía delincuencia profesional ${ }^{6}$.

Aunque solian tener un carácter rural ${ }^{7}$, en las ciudades también se registraban actos similares, que consistían en pequeños hurtos de chatarra, carbón, piezas o materias primas ${ }^{8}$. Había incluso niños que pasaban por los tribunales tutelares de menores por este tipo de actividades. En 1940 bandas infantiles se dedicaban al robo de bombillas en las escaleras de los portales o a realizar pequeños hurtos en los muelles de las estaciones ferroviarias ${ }^{9}$. En algunas ocasiones, los hurtos domésticos tenían una etiología semejante, y las criadas sustraían de las casas donde trabajaban alimentos para sus novios ${ }^{10}$. Provocados por la miseria, los robos de subsistencia persistieron en provincias como Badajoz, Cádiz o Sevilla durante los años sesenta. El paro estacional inducía a las familias a sustraer productos agrícolas, pero ya sin la intensidad del período anterior. En el decenio de 1960, la sustracción de frutas, carbonilla, chatarra, llamadores, tuberías, etc, actos cometidos por las privaciones y asimilados al «hurto famélico", se producirian esporádicamente al mejorar las condiciones de vida desde los oscuros años de la postguerra $^{11}$.

6 Rivera Beiras, I.: “Sociología de la cárcel», en Añón, M. J.; Bergalli, R; Calvo, M; Casanovas, P. (coords.): Derecho y sociedad, Valencia, Tirant lo Blanch, 1998, p. 609. Otros estudios de carácter local corroboran, para los casos de Lérida y Albacete, la importancia alcanzada por este tipo de delitos en los años cuarenta, MIR, C.: «El sino de los vencidos: la represión franquista en la Cataluña rural de posguerra" en CASANOVA, J. (coord..): Morir, matar, sobrevivir. La violencia en la dictadura de Franco, Barcelona, Crítica, 2000 , p. 129 y Ortiz HeRAS, M.: Violencia política durante la /l república y el primer franquismo, Madrid, Siglo XXI, 1996. Sobre el universo carcelario durante la dictadura franquista, MoLINERo, C; SALA, M. Y. SOBREQUES, J. (eds.): Una inmensa prisión. Los campos de concentración y las prisiones durante la guerra civil y el franquismo, Barcelona, Crítica, 2003.

7 Por ello, la mayoría de los presos, antes de entrar en prisión, tenían como ocupación principal la agricultura o la ganadería, en VINUESA, A.G: "La ganaderia en las prisiones", Revista de Estudios Penitenciarios, $n .{ }^{\circ} 36$, (1948), así como ARROYO ARROYO, L.: «El problema de los delincuentes rurales» Revista de Estudios Penitenciarios, $n .^{\circ} 13,(1946)$, pp. 84-86.

a Según BABIANO MORA, J.: Emigrantes, cronómetros y hueigas. Un estudio sobre el trabajo y los trabajadores durante el franquismo, Madrid, Siglo XXI, 1992, p. 214.

9 Tribunal Tutelaf de Menores de MadRid: Memoria del año 1940 que presenta al Consejo Superior el Juez de Menores don Ramón Alberola Such el 31 de marzo de 1940, Madrid, 1941, p. 33.

$10 \mathrm{Cfr}$, ANGÓN: "Los hurtos domésticos", Revista de estudios penitenciarios, n. ${ }^{\circ} 38,(1948)$, p. 105.

1 Según deducimos de las observaciones hechas por el Fiscal General del Estado en FISCALIA DEL Tribunal SuPREmo (a partir de ahora FTS): Memoria elevada al Gobiemo Nacional en la solemne apertura de los tribunales el dia 15 de septiembre de 1964 por el Fiscal del Tribunal Supremo Excmo. Sr. D. IIdefonso Alamillo Salgado, Madrid, Instituto Editorial Reus, 1964, p. 146 y FTS: Memoria elevada al Gobierno Nacional en la solemne apertura de los tribunales el día 15 de septiembre de 1970 por el Fiscal del Tribunal Supremo Excmo. D. Femando Herrero Tejedor, Madrid, Instituto Editorial Reus, 1970, p. 110. 
Los actos de esta naturaleza fueron severamente castigados por los tribunales. La práctica judicial en estos delitos era "sumamente rígida (e incluso) inhumana»", convirtiéndose en una forma más de violencia económica sobre la población ${ }^{13}$. Ante la ineficacia para solucionar los problemas estructurales de la economia, la dictadura aplicaba la represión como respuesta, convirtiendo, como en este caso, a las víctimas en culpables. El franquismo acentuaba así su carácter represivo, en detrimento de otra faceta más tuitiva, de cara a los más débiles de la sociedad, que en la posguerra coincidían con los vencidos ${ }^{14}$. El Estado buscaba la ejemplaridad social porque los autores de este tipo de robos no formaban parte de los sectores sociales protegidos por el régimen. Por el contrario, cuando la víctima era el propio Estado, y por consiguiente los intereses generales, la administración de justicia no se aplicaría en el castigo con la extrema dureza que en los delitos anteriores, como vamos a ver, tanto en el robo de energía como en los delitos cometidos por la burocracia estatal.

En el mismo contexto de precariedad de las infraestructuras y de economía autárquica se sitúan los fraudes de energía eléctrica. Pero a pesar de ser un grave problema, no serían perseguidos por la justicia con idéntico rigor que los hurtos de subsistencia ${ }^{15}$. El fiscal general del Estado expresaba en 1941 su preocupación por este tipo de delitos en los siguientes términos:

«Estos fraudes (...) causan positivos perjuicios a las empresas hasta el punto de que las que funcionan en Madrid calculan las pérdidas sufridas en estos últimos años en varios millones de pesetas. Alcanzan también los perjuicios, en cuantía no pequeña a la hacienda pública, que ha de percibir los correspondientes impuestos establecidos sobre el consumo de fluido eléctrico, que es de primera necesidad en el orden público. $Y$ constituyen, por último, una perniciosa inmoralidad, ya que algunas gentes se habitúan a considerar, como poco menos que lícitos, el realizar en los hogares toda clase de artimañas para utilizar la energía eléctrica, sin sujetarse al pago del canon correspondiente, inaceptable conducta que se traduce en considerar que no es punible el hecho de hurtar cuando las víctimas son grandes empresas y el propio Estado" ${ }^{16}$.

12 Cfr, Rodríguez Devesa: «Necesidades de un nuevo planteamiento del hurto famélico», cit., p. 495.

13 Michel Richards refiere otros actos cotidianos de violencia económica, como el despojar a las familias de los presos de los bienes que poseian, dejándoles en una situación de precariedad y marginación social, o el que se diera carta blanca a los falangistas para presentarse en las casas y apoderarse de lo que quisieran, en RichARDS, M.: Un tiempo de silencio. La guerra civil y la cultura de la represión en la España de Franco, 1936-1945. Barcelona, Crítica, 1999, p. 55.

14 Refiriéndose a otros delitos, Conxita Mir llega a la conclusión de que los grupos para los que la supervivencia era especialmente dura, en la inmediata postguerra veían agravadas sus dificultades si tenían un pasado republicano personal o familiar, en MIR, C: “Justicia y control moral de la población marginal en el franquismo de posguerra", Historia Social, n. 37 (2000), p. 54.

15 Debido a la insuficiencia de las disposiciones legales y a la precariedad de las infraestructuras. De haber ocurrido lo contrario se habrian paralización muchas industrias y un elevado número de localidades habrían quedado sin fluido eléctrico, según la fiscalía, en FTS: Memoria elevada al Gobiemo Nacional en la solemne apertura de los tribunales el día 15 de septiembre de 1951 por el Fiscal del Tribunal Supremo Excmo. Sr. Don Manuel de la Plaza Navarro, Madrid, Instituto Editorial Reus, 1951, pp. 69-71.

${ }^{16}$ Cfr., FTS: Memoria elevada al Gobiemo de la Nación en la solemne apertura de los tribunales el día 15 de septiembre de 1942 por el Fiscal del Tribunal Supremo Blas Pérez González, Madrid, Instituto Editorial Reus, 1942, p. 148. A estos delitos se refiere también en FTS: Memoria elevada al Gobiemo Nacional en la solemne apertura de los tribunales el 15 de septiembre de 1952 por e Fiscal del Tribunal Supremo Excmo. Don Manuel de la Plaza Navarro, Madrid, Instituto Editorial Reus, 1952, pp. 69-71. 
Además de la miseria, durante el período de la autarquía la corrupción se traduciría en una serie de actividades delictivas en las que estuvieron implicados los funcionarios. Sus autores habian sido reclutados después de la Guerra Civil, como premio por los servicios prestados al bando vencedor durante el conflicto bélico. Por ello, el fiscal general del Estado se mostraba preocupado por la proliferación de robos, malversaciones, cohechos y falsificaciones cometidos por funcionarios que, según su testimonio, habian sido "reclutados de cualquier manera $(y)$ se valían de su cargo con el pretexto de lo exiguo de su retribución e intentaban complementarla por medios ilícitos" ${ }^{17}$.

Conviene fijarse al respecto en la denuncia continuada en un documento oficial de la importancia de las Memorias Anuales, elaboradas por la Fiscalía a partir de las informaciones suministradas por los fiscales provinciales sobre la evolución de la delincuencia. La insistencia en sucesivos años demuestra el escaso interés del régimen por atajar la impunidad con que actuaba una burocracia reclutada por su adhesión política y no por su cualificación técnica, así como un ejercicio del poder que consentía, a sabiendas, la corrupción en la administración. El desinterés por acabar con esta actividad delictiva de tan graves consecuencias para el país, y que tenia lugar en el corazón mismo del Estado, contrasta con el rigor con que se castigaban actos de tan escasa relevancia social como los robos de subsistencia. Pero a diferencia de los autores de los "hurtos famélicos", la burocracia culpable de estos delitos constituía un grupo protegido, al que se premiaba haciendo la vista gorda ante la corrupción funcionarial.

Desde el final de la Guerra Civil y hasta 1952, la corrupción fue un hecho generalizado e intenso, que resultaba muy difícil ocultar. Posteriormente, se concentraría en el tráfico inmobiliario ${ }^{18}$. Las fuentes judiciales evidencian la alarma social que la corrupción administrativa producía, y a través de algunos ejemplos, podemos conocer sus formas de funcionamiento. Apenas terminada la guerra, el racionamiento de artículos de primera necesidad se mantendría hasta 1953. La política económica autárquica provocaria la aparición de un importante mercado negro, en el que se conseguían los productos sometidos a racionamiento. En este contexto tendrían lugar los delitos cometidos por la burocracia. Así era, pues los nuevos empleados públicos falsificaban documentos oficiales de abastos, cartillas de racionamiento, guías, declaraciones o carnets de Falange, que utilizaban para hacerse pasar por agentes de abastos y obtener productos intervenidos, según denunciaba en varias ocasiones el fiscal general del Tribunal Supremo ${ }^{19}$.

17 Cir., FTS: Memoria elevada al Gobierno de la Nación en la solemne apertura de los tribunales el dia 15 de septiembre de 1952, cit., p. 87.

18 Según Barciela, C.: «Franquismo y corrupción económica», Historia Social, n . 30, (1998), pp. 8395. Del mismo autor también, «la España del Estraperlo», en García Delgado, J. L. (ed.): El primer franquismo. España durante la Segunda Guerra Mundial. V Coloquio de Historia Contemporánea de España, Madrid, Siglo XXI, 1989, pp. 105-123. También, Michael Richaros, cit.

19 FTS: Memoria elevada al Gobiemo Nacional en la solemne apertura de los tribunales el día 16 de septiembre de 1940 por el Fiscal del Tribunal Supremo Blas Pérez González, Madrid, Instituto Editorial Reus, 1940, p. 40 y FTS: Memoria elevada al Gobiemo Nacional en la solemne apertura de los tribunales 
El Servicio Nacional del Trigo y el Comisariado General de Abastos y Transportes estaban encargados de la distribución de alimentos, pero casi una tercera parte de la producción terminaba en el mercado negro. El sistema de controles favorecía la corrupción, fomentada por la burocracia, como ocurrió en 1941 cuando una partida de centeno, depositada provisionalmente por el Servicio Nacional del Trigo en casa de un particular, no fue recogida en plazo. Al cabo de algunos días, una persona con una orden falsificada del Servicio se presentó a retirarla para su posterior venta ${ }^{20}$.

Otras veces, los funcionarios incumplían las medidas reguladoras de la distribución de productos racionados. De este modo, un secretario municipal que custodiaba una partida de alimentos para escolares procedente de la ayuda americana la repartió entre el alcalde, tres concejales y el auxiliar del ayuntamiento, en lugar de entregarla para su distribución ${ }^{21}$. Lo que demuestra no sólo el conocimiento sino incluso la implicación del poder político en la corrupción administrativa, pues lejos de atajarla se beneficia de ella, como era el caso de estos regidores municipales.

Otros ejemplos ocurridos en los años cuarenta, denunciados por la Fiscalía del Tribunal Supremo, se produjeron cuando un empleado público sustraía vales de gasolina, que vendía a un precio superior en el mercado negro. Las irregularidades en el suministro de fuel-oil se repetirían en la Delegación Provincial de CAMPSA de Barcelona, donde el funcionario encargado del abastecimiento se beneficiaba con 0,25 pesetas por cada kilo de combustible que distribuía con diligencia a quienes accedían a su chantaje, mientras que rompía las peticiones de los que se negaban a pagar esta ilícita comisión ${ }^{22}$. En el Ayuntamiento de Málaga se registraron diversos casos de malversación por un importe superior a 100.000 pesetas. El funcionario encargado del Negociado de Plusvalía y el depositario municipal, que se ausentó sin que la policia demostrara diligencia en buscarle, eran los autores, pero varios recaudadores y el jefe del negociado estaban también implicados ${ }^{23}$.

Depurados tras la guerra los viejos cuadros burocráticos, los funcionarios de nuevo cuño penetraban en los fondos de sindicatos y en otros organismos en los que cometían robos, como el jefe provincial de la Obra Sindical de Guadalajara y posterior secretario provincial de Sindicatos, que entre 1942 y 1949 se apropió de fondos del Instituto Nacional de Previsión, destinados al pago de subsidios fami-

el dia 16 de septiembre de 1946 por el Fiscal del Tribunal Supremo Excmo. Sr. D. Manuel de la Plaza Navarro, Madrid, Instituto Editorial Reus, 1946, p. 85.

${ }_{20}$ Véase en FTS: Memoria elevada al Gobierno Nacional en la solemne apertura de tribunales el día 15 de septiembre de $1942 . . .$, cit., pp. 65-66.

21 "Malversación. Sentencia de 18 de diciembre de 1958", Boletín de información del Ministerio de Justicia, n. ${ }^{\circ} 441,(1959)$, p. 23.

22 FTS: Memoria elevada al Gobiemo Nacional en la solemne apertura de tribunales el día 15 de septiembre de $1952 . . .$, cit., p. 87.

${ }^{23}$ FTS: Memoria elevada al Gobiemo Nacional en la solemne apertura de los tribunales el día 15 de septiembre de 1942 ..., cit., p. 66. 
liares a los beneficiarios de la rama agropecuaria. Igualmente, un oficial administrativo de la misma entidad se adueñó de caudales públicos que debían haberse ingresado en un banco. Un oficial de justicia cometía otro robo al apropiarse del dinero entregado por un litigante como pago de lo que se le reclamaba en el juicio ${ }^{24}$. Un funcionario de la Comisaría General para la Ordenación Urbana de Madrid incluía a los recomendados de un familiar con el que había contraído una deuda, en una lista de expropiados por la institución, para que el organismo oficial les facilitase una vivienda ${ }^{25}$.

Como puede apreciarse por los ejemplos expuestos, los delitos por tráfico de alimentos de primera necesidad, de combustible o de vivienda resultaban muy significativos en una sociedad lastrada por las privaciones. Asimismo, la ineficiencia burocrática y la corrupción administrativa que protagonizaron numerosos empleados públicos, encaramados al Estado por el franquismo, son señas de identidad del período de la autarquía ${ }^{26}$. La alarma social que producían fue denunciada públicamente por el fiscal general del Estado. A ellos incluso se referian las revistas editadas por el Ministerio de Justicia ${ }^{27}$. El poder político estaba pues al tanto de la corrupción administrativa, protagonizada por una burocracia de reciente ingreso. La corrupción se traducía en figuras delictivas como robos, malversaciones, cohechos $y$ falsedades.

A partir de la década de los sesenta la corrupción se especializaría sobre todo en los intereses inmobiliarios. Por ello, las grandes ciudades industriales a las que se trasladaban los emigrantes rurales, convertidas en el escenario de un intenso proceso urbanizador, experimentarán el incremento de la especulación y de las estafas inmobiliarias. De este modo proliferaron los fraudes colectivos en la compra de viviendas, en las que se incumplían las condiciones pactadas con los clientes. La alarma social que producían hizo que, entre 1965 y 1967, la Fiscalía del Tribunal Supremo solicitara al Gobierno medidas preventivas contra esta clase

24 "Sentencia de 14 de marzo de 1961. Ponencia del Magistrado Alejandro García Gómez», Boletín de Información del Ministerio de Justicia, n. 519 (1961), p. 14; «Falsedad y malversación. Sentencia de 22 de septiembre de 1961. Ponencia del magistrado Antonio Codesio Silva», Boletín de Información del Ministerio de Justicia, n. 535 (1961), p. 27; "Malversación de caudales públicos. Sentencia de 11 de abril de 1964. Ponencia del Magistrado José Maria Gonzáles Díaz», Boletín de Información del Ministerio de Justicia, n. ${ }^{\circ} 629$ (1964).

${ }_{25}$ Véase «falsificación de documentos públicos u oficiales. Sentencia de 7 de julio de 1954», Boletín de Información del Ministerio de Justicia, n. 278 (1954), pp. 22-23.

26 Véase FTS: Memoria elevada al Gobierno Nacional en la solemne apertura de tribunales el 15 de septiembre de 1949 por el Fiscal del Tribunal Supremo Excmo. Sr. D. Manuel de la Plaza Navarro, Madrid, Instituto Editorial Reus, 1949. También, FTS: Memoria elevada al Gobierno Nacional en la solemne apertura de los tribunales el 15 de septiembre de 1942..., cit., pp. 65-66; FTS, Memoria elevada al Gobierno Nacional en la solemne apertura de los tribunales el 15 de septiembre de 1940..., cit., p. 4, FTS: Memoria elevada al Gobiemo Nacional en la solemne apertura de los tribunales el día 16 de septiembre de $1946 . . .$, cit., p. 85.

${ }_{27}$ VEGA, J: “Tráfico ilegal y mercado negro", Revista de Estudios Penitenciarios, n. ${ }^{\circ} 64$ (1950), pp. 61-66. Asimismo FTS: Memoria elevada al Gobiemo Nacional en la solemne apertura de los tribunales el dia 15 de septiembre de 1947 por el Excmo. Sr. D. Manuel de la Plaza Navarro, Madrid, Instituto Editorial Reus, 1947, p. 33; FTS: Memoria elevada al Gobiemo Nacional en la solemne apertura de los tribunales el día 15 de septiembre de $1952 \ldots$, cit., p. 87. 
de delincuencia ${ }^{28}$. En Barcelona abundaban las estafas inmobiliarias, como la de la cooperativa SAICA, que perjudicó a 1200 beneficiarios. La Audiencia de Barcelona dictó en este caso sentencia condenatoria, ratificada después por el Tribunal Supremo. Asimismo, la Fiscalía denunciaría la inquietud por una estafa en la construcción de viviendas en 1967. Dado el elevado número de perjudicados, 10.825, repartidos por todo el país, se nombró un juez especial ${ }^{29}$. El fiscal de San Sebastián denunciaba también en 1963 a una constructora por escriturar pisos muy por encima de su valor. Además de las estafas en la construcción y en las calidades de edificación, la escasez de viviendas tuvo otras repercusiones criminales. Por ejemplo, las imprudencias de los arquitectos y aparejadores que dirigian a la vez varias obras, «sin la atención que esto requiere y con el consiguiente peligro para la vida del productor", provocando muchas muertes y lesiones de trabajadores ${ }^{30}$. Asimismo, esta actitud negligente era el motivo del derrumbamiento de edificios a los pocos años de su construcción, con los consiguientes perjuicios para sus propietarios ${ }^{31}$.

Como en el caso de los robos de subsistencia, el Estado franquista criminalizaba a los sectores sociales más débiles, que eran víctimas de la escasez de viviendas. La propia burocracia judicial denunciaba la ineficacia de esta estrategia, pues en vez de abordar las causas del problema, se utilizaba la represión como mecanismo de actuación según se desprende del testimonio de la Fiscalía:

«El gran problema de la vivienda ha hecho que las buenas intenciones se hayan ahogado en un clima de indiferencia social y de falta de cooperación con las autoridades judiciales por parte de los interesados y aún terceros, debido a la si-

28 FTS: Memoria elevada al Gobiemo Nacional en la solemne apertura de tribunales el dia 15 de septiembre de 1969 por el Fiscal del Tribunal Supremo Excmo. Sr. D. Francisco Herrero Tejedor, Madrid, Instituto Editorial Reus, 1969, p. 15 y FTS: Memoria elevada al Gobierno Nacional en la solemne apertura de los tribunales el 15 de septiembre de 1970, cit., p. 247.

29 La intervención de la justicia permitió la identificación de los perjudicados, concretar la cuantía del fraude para cada uno, el procesamiento de cinco personas y la adopción de medidas para terminar una serie de bloques que ya se habían empezado, la entrega de pisos a más de 600 destinatarios, así como la conservación de materiales y la resolución de algunos problemas de titularidad de los solares. Véase FTS: Memoria elevada al Gobierno Nacional en la solemne apertura de tribunales el día 15 de septiembre de 1963 por el Fiscal del Tribunal Supremo Excmo. Sr. D. Ildefonso Alamillo Salgado, Madrid, Instituto Editorial Reus, 1963, pp. 26; FTS: Memoria elevada al Gobiemo Nacional en la solemne apertura de tribunales el dia 15 de septiembre de 1967 por el Fiscal del Tribunal Supremo Excmo. D. Fernando Herrero Tejedor, Madrid, Instituto Editorial Reus, 1967, p. 29 y FTS: Memoria elevada al Gobierno Nacional en la solemne apertura de tribunales el día 16 de septiembre de 1968 por el Fiscal del Tribunal Supremo Excmo. Sr. D. Femando Herrero Tejedor, Madrid, Instituto Editorial Reus, 1968, pp. 5356.

30 Ctr., FTS: Memoria elevada al Gobierno Nacional en la solemne apertura de los tribunales por el fiscal del Tribunal Supremo Excmo. Sr. D. Fernando Herrero Tejedor el dia 15 de septiembre de. 1971. Madrid, Instituto Editorial Reus, 1971, pp. 306. También FTS: Memoria elevada al Gobierno Nacional en la solemne apertura de tribunales el día 15 de septiembre de 1968..., cit., pp. 218-229.

31 El afán desmedido por la obtención de beneficios y la especulación que rodeó la construcción de viviendas, incrementó la criminalidad culposa por el creciente número de accidentes laborales, debido a la negligencia de quienes estaban obligados a adoptar medidas de seguridad, según denunciaba la FTS: Memoria elevada al Gobierno Nacional en la solemne apertura de tribunales el 15 de septiembre de 1967..., cit., p. 27; FTS: Memoria elevada al Gobierno Nacional en la solemne apertura de tribunales el 15 de septiembre de 1968..., cit, pp. 62-63; FTS: Memoria elevada al Gobierno Nacional en la solemne apertura de tribunales el 15 de septiembre de 1971..., cit., pp. 281-282. 
tuación de agobio (...) que sólo cesará cuando desparezca su causa. Es decir, la solución al problema no estaba en el establecimiento de un delito ni en la imposición de sanciones sino en función de fenómenos sociales o económicos al margen de la ley positiva»32.

Por ello, los ciudadanos no denunciaban los abusos de los que eran objeto por el "cobro de primas por arriendo o subarriendo de viviendas" 33 , otra figura delictiva. Es decir, el cobro de una renta diferente del alquiler cuando se arrendaba una vivienda constituia un delito, pero las víctimas no denunciaban los hechos. La explicación está en las condiciones de hacinamiento en las que residian las familias, compartiendo pequeños espacios, debido a la dificultad para encontrar una casa, que era asimismo la causa de reyertas entre inquilinos, que acababan en delitos contra las personas, en ciudades como Burgos o Bilbao ${ }^{34}$.

A partir de los años sesenta, los comportamientos delictivos resultarán novedosos con respecto al periodo precedente. Frente al carácter rural de la criminalidad de la etapa autárquica, en el período del desarrollismo tendrán un carácter urbano, dando paso a una delincuencia de "gentes de mayor categoría social» ${ }^{35}$. La actividad delictiva se modificará en función de varios factores que transformarán la sociedad y serán, a su vez, expresión de su desarrollo: la urbanización, los movimientos migratorios, la industrialización, la extensión del uso del automóvil y el avance experimentado por el turismo.

Las autoridades judiciales franquistas consideraban el turismo, la emigración y el uso del automovil factores ambivalentes. Por un lado representaban la prosperidad social y el descenso de una criminalidad primitiva, ligada a la miseria del período autárquico. Por otro, darían paso a otra nueva, propia de una sociedad más industrial, en la que el número de procedimientos judiciales dependía del grado de concentración urbana, de la existencia de vías de comunicación y del paso fre-

32 FTS: Memoria elevada al Gobiemo Nacional en la Solemne apertura de los tribunales el día 15 de septiembre de 1952, cit., p. 132.

${ }^{33}$ En la ley de 27 de abril de 1946 se prohibía obtener beneficios distintos del de la renta por la celebración de un contrato de arrendamiento, se consagraba pues «la ilicitud del traspaso o cesión de viviendas mediante dádiva y la exigencia de prima por arrendarlas o subarrendarlas, y reputa coautor del delito a cualquiera que por estos procedimientos tortuosos obtenga un lucro que la norma legal declara ilegítimo", cfr., FTS: Memoria elevada al Gobiemo Nacional en la solemne apertura de tribunales el día 15 de septiembre de 1968..., p. 229. A este tipo de delitos se consagraban los articulos RULL VILLAR, B.: "El arrendamiento de vivienda con pago de prima", Revista de Estudios Penitenciarios, n. 15 (1946), p. 33. También "alteración del precio de las cosas, arriendo, subarriendo y traspaso de viviendas mediante el percibo de una prima - Sentencia de 29 de enero de 1955-", Boletín de Información del Ministerio de Justicia, (1955), pp. 28-29.

34 FTS: Memoria elevada al Gobierno Nacional en la solemne apertura de tribunales... 1967, cit., p. 42; FTS: Memoria elevada al Gobierno Nacional en la solemne apertura de tribunales... 1969, cit., p. 30; FTS: Memoria elevada al Gobiemo Nacional en la solemne apertura de tribunales el 15 de septiembre de 1952..., cit., p. 81; FTS: Memoria elevada al Gobiemo Nacional el día 15 de septiembre de 1966 en la solemne apertura de tribunales por el Fiscal del Tribunal Supremo Excmo. Sr. D., Madrid, Instituto Editorial Reus, 1966, p. 144.

${ }_{35}$ Cfr. Onacha Santamaría, C.: "El engaño en el delito de estafa», Boletin de Información del Ministerio de Justicia, 1017 (1975), pp. 4-12. 
cuente de vehículos de motor. Así, la extensión del automóvil provocaba un crecimiento espectacular de los delitos por infracciones circulatorias. De este modo, los juzgados quedaban colapsados por este tipo de asuntos, que absorbían gran parte de la actividad judicial, en las dos últimas décadas de la dictadura ${ }^{36}$.

El incremento del parque automovilístico y la inadecuación de las infraestructuras viarias originaban numerosos accidentes, que desembocaban en actuaciones judiciales. Asimismo, la conducción ilegal sin el permiso reglamentario hacía crecer los sumarios en muchas provincias como Cáceres, La Coruña, Lérida, Málaga, Palencia, Pamplona, Guipuzcoa, Santa Cruz de Tenerife, Tarragona y Toledo. La impaciencia de los aspirantes a conductores, que comenzaban a conducir sin obtener el permiso bien por falta de información o debido a su analfabetismo, que les impedia conseguirlo, incrementaban las infracciones relacionadas con el tráfico circulatorio ${ }^{37}$. Se denunciaba también como novedosa la existencia de "conductores gamberros", que ebrios, conducían en las ciudades como si participaran en una competición deportiva, poniendo en peligro su vida y la ajena ${ }^{38}$.

Por otra parte, en los años sesenta, el turismo experimentó también un espectacular desarrollo. Además de las repercusiones económicas tuvo otras consecuencias sociales, de modo que los fiscales provinciales pensaban que «no eran divisas todo lo que reluce en él (...) el oro también tiene su escoria" ${ }^{39}$. Los turistas podían ser sujetos activos o pasivos de infracciones penales. En ciudades como Alicante o Palma de Mallorca, con una elevada presión turística, se incrementaba la criminalidad por el aumento de la población flotante de origen extranjero. Mientras que en ciudades del interior como Ávila o Guadalajara, sin apenas visitantes, se registraban muy pocos delitos, a excepción de los relacionados con infracciones automovilísticas ${ }^{40}$. El turismo tenía, desde el punto de vista criminal, tres consecuencias: la elevación del número de accidentes de circulación, el incremento de robos y «la relajación de costumbres".

En los juzgados de zonas turísticas como la Costa Brava, Pontevedra o Murcia se elevaba el número de accidentes de tráfico por la indisciplina de los conductores extranjeros, irrespetuosos con las normas de circulación. La mayoría de los delitos cometidos por los turistas eran infracciones de la Ley del Automóvil, seguidos de

36 TOHARIA, J. J.: Cambio y vida jurídica..., cit.

37 FTS: Memoria elevada al Gobiemo Nacional en la solemne apertura de tribunales el día 15 de septiembre de 1973 por el Fiscal del Tribunal Supremo Excmo. Sr. D. Femando Herrero Tejedor, Madrid, Instituto Editorial Reus, 1973, pp. 55-63. «Conducción ilegal.-Sentencia de 6 de mayo de 1966», Boletín de Información del Ministerio de Justicia, n. 722 (1967), pp. 41-42.

38 "Imprudencia temeraria. Sentencia de 22 de diciembre de 1960 ", Boletín de Información del Ministerio de Justicia, n. 507 ( 1961), p. 22.; “/mprudencia temeraria. Conducción de vehículo en estado de embriaguez-Sentencia de 6 de mayo de 1966", Boletín de Información del Ministerio de Justicia, 722 (1967), pp. 40-41.

${ }_{39}$ Cfr., FTS, Memoria elevada al Gobierno Nacional en la solemne apertura de tribunales el 15 de septiembre de $1964 \ldots$, cit., p. 150.

40 FTS: Memoria elevada al Gobierno Nacional en la solemne apertura de tribunales el 15 de septiembre de 1962 por el Fiscal del Tribunal Supremo Excmo. Sr. Don lldefonso Alamillo Salgado, Madrid, Instituto Editorial Reus, 1962, p. 73. 
delitos contra la propiedad. En cuanto a los primeros, la residencia de sus autores en el extranjero dificultaba la actuación de la justicia, así como el resarcimiento de los daños producidos a los perjudicados ${ }^{41}$.

El robo de objetos se incrementaba durante el verano en provincias de la costa como Barcelona, Tarragona, Gerona o Málaga. Ladrones profesionales se trasladaban hasta sus campings, hoteles y playas y delinquian al amparo de la impunidad que les ofrecían las grandes aglomeraciones, pues los mismos efectivos policiales vigilaban a varios millones más de personas. Los turistas víctimas de delitos eran refractarios a denunciarlos por las incomodidades que les producían, lo que generaba un clima de impunidad para los malhechores. A veces los extranjeros tenían comportamientos delictivos, pues simulaban sufrir robos para al regresar a su país cobrar los correspondientes seguros por cámaras de fotos, tomavistas o transistores.

Una última consecuencia, siempre según la fiscalía, era la "relajación de costumbres", que los turistas exhibían en playas y otros lugares. Los responsables de justicia consideraban que atenuaba los frenos morales e incitaba a su imitación, de modo que era un mal ejemplo para los jóvenes ${ }^{42}$ :

«En las zonas de turismo, tan influencias por las costumbres extranjeras, se va perdiendo, poco a poco, la conciencia de la moral, de tanto y tan buen arraigo en las buenas costumbres españolas: hoy desgraciadamente, las gentes no se escandalizan por nada, manifestando una peligrosa indiferencia ante la presencia de homosexuales y prostitutas, que no se recatan de hacer alardes públicos de su repugnante personalidad, problemas que dominan el ambiente de frivolidad que se vive en estas tierras influenciadas por el turismo y constituyen una tremenda preocupación para todas las autoridades civiles y religiosas, que, pese a su esfuerzo por impedirlo, no han conseguido atajar este grave peligro, de tanta trascendencia moral y social "43.

Los movimientos migratorios, tanto los interiores como los exteriores, experimentarán un desarrollo espectacular a partir de la década de los años sesenta. Sus repercusiones sociales y administrativas serán importantes. Además de la creación en 1956 una agencia estatal especializada en la gestión de los flujos migratorios, el Instituto Español de Emigración, así como de un Juzgado Especial de Emigración. Los movimientos de población interiores produjeron modificaciones en la estructura de los juzgados y en la demarcación judicial. A partir de la segunda mitad de la década de los sesenta, la administración de Justicia se concentraba en las ciudades, de modo que se suprimían juzgados de partido

41 Según De Paado Peñarrubia, A: “El turista extranjero y sus responabilidades" Boletín de Información del Ministerio de Justicia, n. ${ }^{\circ} 355$ (1956), pp. 3-7.

42 A este aspecto ya nos referimos en FERNANDEZ AsPERILLA, A: "Justicia y sociedad bajo el franquismo: de la ley de vagos y maleantes a la ley de peligrosidad y rehabilitación social", VV.AA.: El régimen de Franco (1936-1975). Congreso internacional, Madrid, UNED, 1993, pp. 87-96.

43 Cfr., FT: Memoria elevada al Gobierno Nacional en la solemne apertura de tribunales el 15 de septiembre de 1964..., cit, p. 150. En similares términos se expresaba la Fiscalía en Memoria elevada al Gobiemo Nacional en la solemne apertura de tribunales el 15 de septiembre de 1969..., cit., p. 35 y Memoria elevada al Gobierno Nacional en la solemne apertura de tribunales el 15 de septiembre de 1962..., cit., p. 66. 
y aumentaban los de las capitales. Asi era, pues la concentración urbana de la población y el despoblamiento de las zonas rurales, acentuaba el carácter urbano de la delincuencia. Pero además de estas repercusiones orgánicas, las migraciones tendrán otras consecuencias sociales. Por un lado, las condiciones de habitabilidad en las grandes urbes se degradarán por la falta de previsión gubernamental, ante la llegada masiva de población a las ciudades industriales. Por otro lado, las migraciones producirán cambios de actitud en las personas al disminuir la presión social que ejercian en las zonas rurales la familia o los vecinos ${ }^{44}$.

Desde el punto de vista de la evolución de la delincuencia, una de las consecuencias de las migraciones era que el descenso de actividades delictivas provocadas por la pobreza, estaba relacionado con el éxodo migratorio exterior. El fiscal de Córdoba manifestaba en los años sesenta que la elevación del nivel de vida y la educación cívica en muchos pueblos y comarcas de la provincia se debía a la emigración laboral a países centroeuropeos:

"No sólo por el contacto de los trabajadores con otros, frecuentemente de superior cultura, sino por la liberación de apuros económicos a las familias con la remesa de auxilios dinerarios. Ello sin contar con que ciertos elementos díscolos y de espiritu aventurero, al señuelo de lo que estimaban fáciles ganancias han abandonado la provincia cordobesa ${ }^{45}$.

Otros fiscales provinciales coincidían en el diagnóstico de que la disminución de la delincuencia se debía al éxodo migratorio. El de Guadalajara afirmaba que su «provincia con precaria vida, sin industria y con constante y aumentado éxodo de emigración, tiene poca delincuencia". En Sevilla, el descenso de algunos tipos de delitos contra la propiedad se debía a las facilidades para emigrar de la mano de obra que el mercado de trabajo no absorbía. En Jaen, la emigración a Francia y Alemania tenía idéntico efecto. En similares términos se expresaba el fiscal de Orense, donde se había intensificado la emigración a América Latina y a países de Europa Occidental. Por último, la disminución en Badajoz de los delitos de hurto era debida a que «las gentes que vivian del trabajo manual salian de la provincia y emigraban, en busca de mejores condiciones, bien al norte de España o al extranjerom ${ }^{46}$.

44 Algunos fiscales, como los de Barcelona o el de Valencia, mostraban su preocupación en los años sesenta por las transformaciones estructurales y las consecuencias sociológicas provocadas por las migraciones. Ambos denunciaban en las grandes concentraciones urbanas, las defectuosas condiciones de habitabilidad, la promiscuidad, la influencia de ambientes extranjeros, la pérdida de los controles clásicos o «el afán por progresar o al menos aprovechar las ventajas que el mundo ofrece con demasiada rapidez y sin esfuerzo». Cfr., FTS: Memoria elevada al Gobiemo Nacional en la solemne apertura de tribunales el 15 de septiembre de $1962 \ldots$ cit., p. 36.

45 Cfr., FTS, Memoria elevada al Gobiemo Nacional en la solemne apertura de tribunales el 15 de septiembre de 1963..., cit., p. 68.

46 Cfr., FTS, Memoria elevada al Gobierno Nacional en la solemne apertura de tribunales el 15 de septiembre de 1964, cit, p. 144. Sobre las ventajas materiales derivadas de la emigración interior, véase Salinas QuIJADA, F: Las migraciones interiores y la delincuencia infantil y juvenil, Pamplona, Aranzadi, 1969. En iguales términos Serrano Gómez, A.: "Criminalidad y movimientos migratorios", Revista Española de la opinión pública, n. ${ }^{\circ} 17$, Julio/septiembre (1969), pp. 19-54. 
La emigración producía también separaciones familiares, que aumentaron los sumarios por abandono de familia, como ocurrió en Córdoba en 1962, debido al gran número de emigrantes de la provincia en Alemania. Asimismo, generaba comportamientos desviados de los patrones oficiales, ocasionando delitos de bigamia, dado que trabajadores españoles casados en su país de origen contraían de nuevo matrimonio en el país de destino. Algunas mujeres solas, debido a la emigración exterior de sus maridos, cometerian delitos de adulterio o ejercerían la prostitución, en algunos casos para completar los recursos económicos insuficientes que el esposo enviaba desde el extranjero. De hecho, la prostitución no se prohibió legalmente hasta 1956, pues se había convertido en una forma de supervivencia de bastantes mujeres y jóvenes marginadas en los duros años de la posguerra ${ }^{47}$. Como se constata, el régimen entendia como delitos lo que no eran sino efectos desgraciados, desde el punto de vista social, de los movimientos migratorios. Y en consecuencia con esa comprensión y a pesar del aparente carácter tuitivo de la legislación protectora de la mujer y la infancia, las víctimas pasaban nuevamente a verse desde el prisma de la criminalización.

El ritmo al que se transformaba la sociedad española resultaba trepidante para los políticos franquistas, que se sentían desbordados. Ante las nuevas realidades surgidas del desarrollo, las élites políticas y la burocracia judicial aplicaban viejas recetas a nuevos problemas. Se intentaban abordar los nuevos fenómenos delictivos actualizando la obsoleta Ley de Vagos y Maleantes. Pero a pesar de su transformación nominal en Ley de Peligrosidad y Rehabilitación Social y de la ampliación de situaciones que contemplaba, en los años sesenta seguía siendo una respuesta represiva.

El estado franquista utilizaba la represión como forma habitual de actuación, tanto contra lo que consideraba delincuencia política como ante carencias sociales de carácter estructural, que hubieran requerido para su remedio otras respuestas gubernamentales. La consecuencia de esta característica del franquismo es que tendía a la criminalización de los débiles y de las víctimas, no sólo en el campo político sino también en el social. Por esta característica de la dictadura, dentro del estado los aparatos de orden represivo eran la parte más desarrollada de la burocracia, frente al entramado de protección social, por ejemplo. Todo ello, evidentemente es también un ingrediente a tener en cuenta a la hora de comprender la naturaleza del régimen.

47 Según ConxiTa MIR: “Justicia civil y control moral...», cit., p. 67. Pensamos que la tardanza en prohibir la prostitución respondía sobre todo a motivos de tipo económico, pues como apunta Mir, muchas mujeres en la postguerra vieron en la prostitución una alternativa para librar de la extrema miseria a sus familias. Además, una diposición prohibitiva tan tardía no encaja dentro de la estricta vigilancia que el régimen ejerció de la moral, sobre todo a partir de 1944. Además, porque el Concordato con la Santa Sede se habia firmados varios años antes, en 1953. 